\section{Local motivations, regional implications: Scaling from local to regional food systems in northeastern North Carolina}

\author{
Gabriel Cumming a * \\ Working Landscapes \\ Sophie Kelmenson b \\ University of North Carolina at Chapel Hill \\ Carla Norwood c \\ Working Landscapes
}

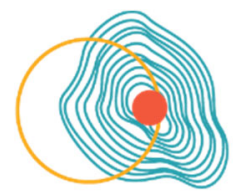

PLACE-BASED FOOD SYSTEMS CONFERENCE: Making the Case, Making it Happen August 9-10th, 2018

Submitted December 14, 2018 / Revised March 5, May 2, and June 5, 2019 / Accepted June 5, 2019 /

Published online August 25, 2019

Citation: Cumming, G., Kelmenson, S., \& Norwood, C. (2019). Local motivations, regional implications: Scaling from local to regional food systems in northeastern North Carolina.' Journal of Agriculture, Food Systems, and Community Development, 9(Suppl. 1), 197-213. https://doi.org/10.5304/jafscd.2019.091.041

Copyright (C 2019 by the Authors. Published by the Lyson Center for Civic Agriculture and Food Systems. Open access under CC-BY license.

\begin{abstract}
In communities across North America, organizations have launched local food system initiatives as a response to the depredations of the globalized agri-food economy; however, they increasingly find that they cannot achieve their desired impacts or sustain their ventures by operating solely within their home communities. Consequently, they embark on regional food system development

a * Corresponding author: Gabriel Cumming, Working Landscapes; 108C South Main Street Suite 2; Warrenton, NC 27589 USA; +1-252-257-0205; gabriel@workinglandscapesnc.org

b Sophie Kelmenson, Department of City and Regional Planning, University of North Carolina at Chapel Hill; New East Building, CB\# 3140, UNC-CH; Chapel Hill, NC 275993140 USA; soph@live.unc.edu

c Carla Norwood, Working Landscapes; 108C South Main Street, Suite 2; Warrenton, NC 27589 USA.
\end{abstract}

initiatives. Drawing upon the experiences of 41 organizations_-including Working Landscapes, a grassroots nonprofit that two authors of this paper

\section{Disclosures}

Two of the authors lead an organization, Working Landscapes, whose work is the subject of this paper. However, the authors do not have any relevant financial or other interests that might be construed as resulting in an actual, potential, or apparent conflict in their roles as authors of the paper.

\section{Funding Disclosure}

This paper is based on work supported by the U.S. Department of Agriculture (USDA), National Institute of Food and Agriculture, under award number 2016-33800-25598 and the USDA Agricultural Marketing Service, under grant AM170100 XXXXG086. Any opinions, findings, conclusions, or recommendations expressed in this publication are those of the authors and do not necessarily reflect the view of the USDA. Additional funding for project activities reported in this paper was provided by the Kate B. Reynolds Charitable Trust. 
direct - this paper examines emerging regional food initiatives in the rural, economically distressed region of northeastern North Carolina. We elucidate characteristics that differentiate regional initiatives from the same organizations' local activities. We find that regional initiatives are motivated by organizations' strategic needs, which are highly variable in spatial scale, largely uncoordinated with each other, and not yet successful in fully achieving their goals. Drawing upon this analysis, we identify opportunities to increase the effectiveness of regional food system initiatives by increasing shared understandings of these initiatives and advancing region-scale planning.

\section{Keywords}

Regional Food Systems, Local Food Systems, Social Networks, Rural, Regional Planning, Scale, Collaboration, Stakeholder Engagement, Value Chains, Food Hubs

\section{Introduction}

Faced with the damage that the global food system has wreaked on their communities, farms, and environment, individuals and organizations across North America have turned to local food systems as an alternative. However, local community-based initiatives are not capable of transforming the supply chains through which most people are getting their food. In order to expand their impact, alternative food organizations are increasingly scaling up to work regionally.

Regional food system development remains poorly understood and conceptualized by both practitioners and researchers. At what scale do systems become regional instead of local? Our findings suggest that, rather than being associated with one specific scale, it is more useful to characterize regional food systems development as a distinct mode of food systems activity. We find that grassroots food system organizations are typically motivated by commitments to a particular local geography (usually county scale or smaller); we characterize their endeavors within this geography as local food systems work. Many of these same organizations, however, are also expanding beyond those locales to serve broader areas, ranging from multiple counties to parts of multiple states; the spatial extents of these initiatives vary based on decision criteria that are distinct from the organizations' local food motivations.

These strategic expansions, which we characterize as regional food system activities, cause new overlaps among organizations' service areas. This creates opportunities for collaboration, but coordinating among multiple intersecting regional initiatives can also bring new challenges. Given that numerous local food organizations are currently navigating emerging regional food economies and the new relationships that accompany them, it is important to understand better their experiences of doing so.

This paper seeks to characterize current food system efforts in northeastern North Carolinawhere exploration of regional food system planning is just beginning - by studying the perspectives and activities of organizations working there. Through mixed-method research, we explore (1) the distinct motivations undergirding these organizations' local and regional food system efforts; (2) how issues of scale are navigated; (3) the degree to which organizations are collaborating regionally; and (4) the degree to which organizations are meeting their own goals (or not). Drawing upon this analysis, we address the need to build constituencies for regional food systems and support their development through coordinated planning.

\section{Literature Review}

Consideration of scale in food systems usually proceeds from a posited dichotomy between "industrial" or "mainstream" agricultural production systems and "local" food systems. Mainstream agriculture is characterized as the oligopolistic, massproduction system that relies on economies of scale within a globalized sourcing system and a national policy framework. ${ }^{1}$ Industrial agriculture has documented connections to increasing reliance on unhealthy, fast food companies (Schlosser, 2001); attendant increases in diet-related health issues such as obesity (Fryar, Carroll, \& Ogden,

\footnotetext{
${ }^{1}$ See Pirog, Miller, Way, Hazekamp, and Kim (2014) for a description of the origins of industrial food.
} 
2010), with particularly worsened outcomes for people of color, people receiving low incomes, and/or people with lower levels of education (Drewnowski \& Spector, 2004; Flegal, Carroll, Kit, \& Ogden, 2012); a decline in the number of small farms and food businesses (Drabenstott, 2001); increased environmental degradation and greenhouse gas emissions (U.S. Environmental Protection Agency [EPA], 2013); increased disparities in neighborhood quality, specifically relating to housing, education, and employment quality; lessened access to healthy food due to discriminatory trends in the geography of food retail (Desjardins, 2010; Truehaft \& Karpyn, 2010; Walker, Keane, \& Burke, 2010); and increased use of discriminatory and unhealthy labor practices in agriculture and foodservice settings (Kelly, Lang, Bhandal, \& Electric, 2012; Martin, 2003).

Local food was initially characterized as part of an "alternative food movement," which reflected the myriad of counter-reactions to the negative impacts of industrial agriculture (Feenstra, 2002; Hinrichs, 2000). While the phrase "local food" implies a geographic range, when used by consumers it is also associated with several nonspatial attributes: local farm ownership; small-scale farm operations; production methods that protect the environment; and foods that have natural, organic, or other "higher quality" attributes (Low et al., 2015). Planners, local governments, and impact investors extoll "local" food for its ability to contribute to the local economy (Kish, \& Fairbairn, 2018; Kneafsey, Ilbery, \& Jenkins, 2001).

Coinciding with these patterns, there is an observed increase in demand for differentiated food in several forms: functional (e.g., specialty, higher-quality ingredients); safe (e.g., antibiotic-free or hormone-free); environmentally sustainable; or from a specific geographic location (Stevenson \& Pirog, 2008). Consumers want high-quality food, produced in a way they are comfortable with, from a producer they can trust (Kirschenmann, Stevenson, Buttel, Lyson, \& Duffy, 2008). These demands contributed to the widespread equation of "local" with direct-to-consumer (DTC) food systems, where the producer sells directly to the consumer (e.g., farmers markets, community supported agriculture operations [CSAs], roadside stands, and/or
U-pick operations), a practice associated with highquality food and sustainable, ethical production.

\section{From Local to Regional}

As demand for locally sourced food increases, there is growing recognition that DTC sales alone cannot meet increasing demand for local food (Born \& Purcell, 2006; Janssen, 2010; Stevenson \& Pirog, 2008). DTC sales grew from US $\$ 551$ million in 1991 to US\$1.2 billion in 2007 (Pansing, Wasserman, Fisk, Muldoon, Kiraly, \& Benjamin, 2013). The number of farmers markets grew 180 percent between 2006 and 2014 (Low et al., 2015). However, the rate of growth in DTC sales between 2007 and 2012 slowed significantly (to US\$1.3 billion), even though the percentage of farms that reported marketing food through farmers markets and intermediated supply chains grew. While this slowdown may be partially attributable to the recession that occurred between December 2007 and June 2009 or a natural plateau in demand reflecting the limits of consumers' purchasing power, it may also suggest that farmers growing for local consumption are increasingly using intermediated channels to sell their products (Low et al., 2015).

Consumers receive local food through intermediated supply chains via businesses such as retail outlets, restaurants, wholesale aggregators, institutional buyers, or food hubs. These intermediated arrangements often require shifting away from the local scale towards a bigger framework of supply, demand, and region of influence; this shift is referred to as increasing in scale. Reasons for growing in scale are well established. Larger-scale intermediated chains are attractive to farmers because they can create efficiencies that decrease marketing and transportation costs, develop additional markets, and stabilize their supply chains (Gwin \& Thiboumery, 2014; Hardesty et al., 2014; PolicyLink, 2001). Efficiencies of scale make production (and sometimes consumption) costs cheaper (Low et al., 2015), and midsize or "mid-tier" or "agriculture of the middle" farms and processors earn higher incomes in local intermediated supply chains (Kirschenmann et al., 2008; Stevenson \& Pirog, 2008).

Growing in scale often requires a regional 
approach, simply to be able to garner the supply and demand necessary to grow. Lev and Stevenson (2011) document "midscale food value chains" 2 operating at a regional level, where farms and ranches, and their associated processing, distribution, and retail businesses, act collectively as bigger than local but smaller than industrial entities. These value chains are strategic alliances among farms and food businesses that handle higher volumes of high quality, differentiated food products, and distribute profits equitably.

The term "regional" is increasingly applied to food system initiatives; however, as Clancy and Ruhf (2018) pointed out in this journal, it is often conflated with local. They argue that additional attention must be paid to the term as a distinct lens through which to view food systems and not just for the economic benefits of creating efficiencies by leveraging infrastructure and market size across space. There are benefits in mobilizing multiple scales of food systems work for its resilience (Whitfield, Challinor, \& Rees, 2018), for better understanding ecosystem-level impacts (Wolfe et al., 2018), and for managing land use patterns and farmland conservation (Clancy et al., 2017), among other dynamic and multiscalar processes. Finally, a regional approach to economic development that encourages connections between urban and rural areas will increase the likelihood of prosperity for those regions (Isserman, 2001; 2005). In sum, viewing local food systems in isolation misses the larger systems they function within and have the potential to affect. Examining whether regional collaboration emerges may shed light on opportunities to better support local food efforts, grow alternative food opportunities, and most importantly, better support the residents of those communities.

Regional food systems work has begun in an explicit manner, but it has been insufficiently theorized. Lengnick, Miller, and Marten (2015) (cited in Clancy \& Ruhf, 2018) describe a selforganizing, regional, cooperative food network that connects smaller towns and bigger cities. Food Solutions New England is a leading example of a formalized regional approach to food systems work, involving coordinated mapping and strategy development to realize a "regional vision" for the food system across the six New England states. The organization also has an established regional food-to-institution supply chain within the same group of states, regular collaborative meetings among policymakers, and an annual regional conference (Food Solutions New England, n.d.). The emergence of phrases such as "city region food systems," "urban-rural linkages," "foodsheds," "bioregions," or "territorial development" indicate interest in approaches to food systems that encompass more than local spatial scales (BlayPalmer, Santini, Dubbeling, Renting, Taguchi, \& Giordano, 2018). Donald (2008) describes emerging "alternative food geographies," constituted as collaborative networks of producers, consumers, and actors. These networks give the local food movement the ability to create equitable outcomes by redistributing value along the value chain instead of directly to commodity producers, as well as creating collaborative processes of governance (Whatmore, Stassart, \& Renting, 2003). While the greatest emphasis has been on local food production, Donald (2008) and Tewari, Kelmenson, Guinn, Cumming, and Colloredo-Mansfeld (2018) point to the (understudied) importance of intermediaries' role in developing processing, distribution and retailing capacity—-the processes needed to expand and enhance alternative food systems.

Questions remain about how regional food systems emerge and function. How do local food value chains interact with one another or local initiatives in emerging regional systems? Developing local or regional food systems work often relies on leadership from within the community, while public universities and institutions may play a role in seeding some of these relationships and infrastructure investments in regional food systems work (Dunning, Bloom, \& Creamer, 2015; Inman, 2015; PolicyLink, 2001). This literature, and much of the literature focusing on the politics of local food, implicitly points to the importance of relationships, and therefore social networks, in initiating new

\footnotetext{
2 "Value chain business models place emphasis on both the values associated with the food and the values associated with the business relationships within the food supply chain” (Stevenson \& King, 2011, p. 27).
} 
food systems from the ground up (Hinrichs, 2010; Tewari et al., 2018; Watson, Treadwell, \& Bucklin, 2018). Building upon this emphasis in the literature, an examination of relationships among stakeholders is central to this study of northeastern North Carolina's regional food system.

\section{Methods: Data Sources and Analyses}

To understand the motivations undergirding local and regional efforts, how organizations navigate issues of scale, and the degree to which organizations are collaborating across the region and meeting (or not) their goals, this paper draws on data collected from 41 organizations in northeastern North Carolina. These data were primarily collected through Growing Opportunities, a research project conducted by Working Landscapes in 2017 and 2018. Additionally, we draw upon Working Landscapes' organizational records to elucidate how one food hub is navigating the regional food system development processes covered in this paper. Drawing on interviews, surveys, focus groups, and business records, our analysis enables us to address our research questions through data "triangulation" (Lincoln \& Guba, 2000; Marshall \& Rossman, 2016). Data collection and analysis methods are discussed below.

Growing Opportunities was designed to advance northeastern North Carolina's emerging regional food system and foster shared understandings of gaps and opportunities in that system. The project focuses on an eight-county region of inner northeastern North Carolina, encompassing Bertie, Edgecombe, Halifax, Hertford, Nash, Northampton, Vance, and Warren counties (see Figure 1). Warren County is the home of Working Landscapes; the other counties were selected because they are demographically similar to Warren and face comparable economic, health, and food access challenges. Growing Opportunities employed the Community Voice Method (CVM), ${ }^{3}$ a participatory research and stakeholder engagement methodology (Cumming \& Holland, 2013; Cumming \& Norwood, 2012).

CVM was developed by two of the authors in 2004 to foster more productive public dialog regarding contentious land use planning debates in western North Carolina. Stakeholder engagement efforts spanning North Carolina, the Turks and Caicos Islands, and the UK have successfully used CVM on topics ranging from food systems to land use planning and marine resource management

\section{Figure 1. Eight-County Project Region in Inner Northeastern North Carolina}

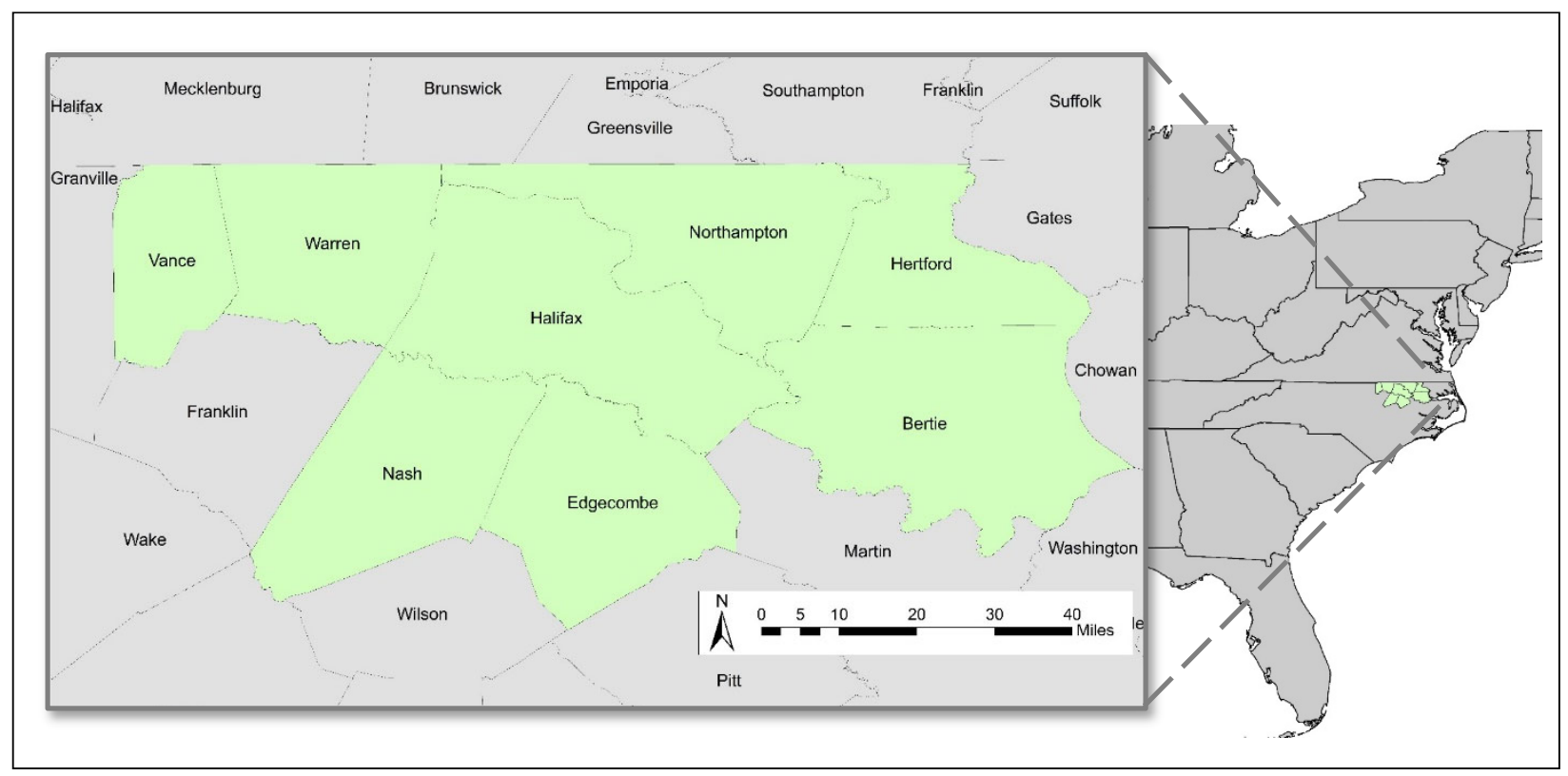

\footnotetext{
${ }^{3}$ See http://communityvoicemethod.org
} 
(Cumming \& Holland, 2013; Cumming \& Norwood, 2012; Ranger et al., 2016). CVM begins by conducting semistructured, video-recorded interviews with diverse stakeholders on a particular topic. Interviews are then transcribed, coded, and analyzed using NVivo software; a combination of inductive and deductive coding is employed (Iloh 2016). This qualitative analysis guides both (1) the production of a film of interview clips, which represents the views expressed in the interviews, and (2) geospatial and quantitative analyses that address issues raised by interviewees (Norwood \& Cumming, 2012). Facilitated workshops then share the film and quantitative data, where a broader range of stakeholders are invited to respond to the presentations, discuss options, and identify solutions to the issues raised.

In Growing Opportunities, the CVM process proceeded as follows. First, video-recorded interviews were conducted with a purposive sample of 14 stakeholders in northeastern North Carolina's food system. Interviewees were selected to represent diverse sectors within food value chains (farming, aggregation, processing, distribution, foodservice), as well as the geographic and demographic diversity of the project region. Interviewees were asked to describe how they became involved in food system work and how their work evolved, offer perspectives on the need for a regional food system, identify opportunities for and challenges to developing that system, and characterize a successful regional food system. Interviews were transcribed and analyzed with NVivo. Interview excerpts were selected as exemplars of these views, and those excerpts were edited into an 18-minute film summarizing interview findings.

Further stakeholder input was collected during a Growing Opportunities meeting held by Working Landscapes on August 28, 2018. The participatory meeting included a screening of the film; a presentation of quantitative data on the region's food system challenges, assets, and opportunities ${ }^{4}$; and facilitated small group discussions and ranking exercises aimed at establishing an action agenda for food system development. Participant characteristics and views were also collected through written pre- and post-surveys.

Working Landscapes recruited participants based on our professional contacts with other organizations working in the eight-county region, as well as recommendations from project participants. Fifty stakeholders representing 38 organizations attended. These respondents play a variety of roles in regional food value chains, including farming (16), aggregation (7), processing (4), distribution (13), procurement (12), and foodservice (4). Many also provide value chain and food system support services such as education (20), technical assistance (25), value chain coordination (12), and funding (13).

A social network analysis (SNA) of Growing Opportunities meeting participants examines the extent to which food system organizations in northeastern North Carolina collaborate regionally. This analysis visualizes and measures relationships across a potential network to assess the connectivity of the network and the centrality of individual organizations. Participants in the meeting were asked to list other organizations with which they work and to characterize their relationships as one or more of the following four categories: 1, "we know each other"; 2 , "we have exchanged information"; 3, "we have collaborated"; and/or 4, "we have transacted food." For the purposes of this SNA, we conducted two network analyses following Kolaczyk and Csardi (2014).

First, we grouped the first three characterizations together hierarchically, each being considered to represent a stronger relationship than the previous. We included the "we have transacted food" characterization as a special type of collaboration, and that relationship was therefore re-coded for the first analysis as a type of collaboration. The relationships in the network analysis were weighted by the relationship characterization, with collaborations indicating the strongest relationship. This analysis aims to describe the structure of the network and whether a regional approach to food

\footnotetext{
${ }^{4}$ The data presentation summarized key economic, agricultural and health statistics for the region from recent US Census, USDA Agricultural Census, and Robert Wood Johnson Foundation Health Rankings, as well as original maps depicting the locations and sizes of schools, hospitals, colleges, prisons, and nursing homes in the region.
} 
systems may be emerging.

The second analysis looks specifically at those organizations transacting food as a way to understand whether and where scale may or may not be occurring in the hypothesized regional food system. The relationships in this second analysis are not weighted, as all the relationships are characterized as having the same strength.

In addition to the Growing Opportunities data, we drew on the sales records and financial projections of Working Landscapes' food hub as empirical data to model the spatial of extent of a hypothetical region that an organization would need to serve in order to scale up under different market scenarios.

\section{Results}

Our results are organized around four questions aimed at characterizing food system initiatives in northeastern North Carolina as those initiatives scale up from local to regional.

1. What are the motivations for organizations' local, place-based work, and are motivations for their regional food system initiatives different?

2. How do local food system organizations conceive of and navigate issues of scale in developing regional initiatives?

3. As organizations scale up, to what extent are organizations whose service regions overlap working together?

4. Are organizations that are pursuing regional food system initiatives achieving their goals?

\section{Motivations for Local and Regional Food Systems Efforts}

Drawing upon the interviews with leaders of food initiatives and enterprises across northeastern North Carolina that were conducted during the initial phase of the Growing Opportunities project, we examined the motivations for their local and regional work. As a point of comparison, we also included our own organization, Working Landscapes. Working Landscapes is a small nonprofit organization based in Warren County, North Carolina, where it works to develop local and regional food systems. It is not by happenstance that Working Landscapes is located in Warren County; its founder and executive director, Carla Norwood, established the organization as a way of making a contribution in her home community, where her family has resided for seven generations.

The interviews revealed that, like Norwood, most Growing Opportunities interviewees (11 of 14) had place-based reasons for engaging in food work in a particular locality. Interviewees had preexisting family connections to the place they work, and they held strong connections to a specific, usually small, locality. Though in many cases they sought economic (livelihood) gains from working in the food sector, their selection of their home communities as a location for their food work was guided by these pre-existing, essentially noneconomic commitments. For example, a hospital administrator described how her loyalty to her community motivates her work on healthy, local food:

I'm from here, and these are my family, friends, and neighbors. ... Eastern North Carolina is largely a farm community, and many of our own employees, our own team members, many of the visitors and patients that come into our hospitals are from those farm families. So those relationships matter to us. It matters to us when they take pride in recognizing that the very food that we're serving... came from their family; it came from their farm.

In some cases, their work represents an extension of unbroken, multigenerational, place-based work in a certain location. This is typical of farmers, as one describes: "My grandparents were farmers. ... Grew up here and it's just been something I always did. I just never left."

In other cases, it represents a return home, as described by the co-founder of a grassroots nonprofit organization involved with food and agriculture:

I can myself identify a situation of blacks coming back to the South and keeping the land, because it was not my intention to come to Henderson and certainly not my intention 
to stay in Henderson, but the family wanted to get rid of the property and the land.... What we realize is that our forefathers and foremothers worked so hard to accumulate those small things... and somebody must take the legacy forward. You can't give it away.... when land is given away, you can't get it back.

Despite being motivated to contribute to a particular place, most of those we interviewed also now engage in food system work that encompasses a broader geography. In every case, the reason is the same: they cannot build resilient food value chains or adequately support their missions by relying solely on their home geographies. One or more links in the chain are missing or are too small to meet the organization's needs. Several examples from the interview data illustrate this phenomenon.

Example 1: A small farmer considers his local food geography to encompass 5 to 10 miles (8 to 16 kilometers), but markets for one of his products, pasture-raised pork, are too small within that radius. He must travel over 50 miles $(80 \mathrm{~km})$ to a regional urban center to generate sufficient sales to support himself.

Example 2: An entrepreneur established multiple food enterprises in her hometown as a way of contributing to downtown revitalization. In order to supply her restaurant with "local" food, however, she must source from across eastern North Carolina.

Example 3: A food hub operator renovated a vacant structure in a small town to house aggregation, processing, and retail operations aimed at increasing access to healthy, local food while also creating job opportunities. The value chains that she has developed to support the hub extend much further, though; she purchases produce throughout eastern North Carolina and supplies wholesale buyers across multiple states.

As the cases above indicate, the organizations' regional initiatives are not just spatially expanded versions of their local activities; they represent a distinct mode of endeavor with distinct motivations. Their local work is typically motivated by pre-existing, place-based, non-economic factors, while their regional work is strategic and opportunistic, reflecting decisions meant to increase the viability of ventures initiated to benefit local geographies. While practical and economical, regional forays do not represent a turn away from the values that guide local food endeavors; instead, they are efforts to sustain those values by enacting them across broader geographies.

\section{Navigating and Defining Scale Across Local and Regional Work}

Consistent with the finding that regional food system initiatives - unlike local food initiatives - are strategic and economic, we find that how organizations define "region" is itself a strategic and fluid exercise. The geographies that interviewees defined as their service "regions" varied widely, ranging from a multicounty area to a large substate area (northeastern North Carolina or, more typically, eastern North Carolina) or even a multistate area.

These stakeholders are not interested in growth for growth's sake. They do not want to scale up indefinitely. Universally, they are not interested in franchising, opening more locations, or going national. They just want to reach a financially sustainable scale that enables them to remain as faithful as possible to their local food commitments. Thus, the size of an organization's service region depends on how far afield that organization must go to become financially viable and support its mission. One farmer put it this way:

It would be easier to get rid of the product [if] you could just go right here in the region and load up, go an hour, two hours at the most, and come back to the farm. That goes back to... your cost, your transport, and then your labor and all, too. If you could get everything to [sell] in the region, 50 miles [ $80 \mathrm{~km}$ ] would be a big plus.

To him, going further to make a sale just represents more cost. If he can make all of his sales within 50 miles, that is preferable.

Conceptions of region vary by organization; they are based on opportunities, strategy, product, 
and/or season. This is illustrated by Working Landscapes' farm-to-school value-added produce operation; based on cash flow data from five years of preparing fresh-cut produce for schools, projections indicate the hub must sell 600,000 pounds (272,155 kilograms) of produce annually to cover operating costs. This level of production would support seven full-time, living-wage jobs. How broad a geography will the organization need to supply in order to support this level of production (and the organization's local community development objectives)? That depends on the depth of the market. The more regionally sourced food that a single customer buys, or the greater the number of proximate customers, the smaller the geography that Working Landscapes will need to operate within.

Taking the example of Working Landscapes' primary customers, school districts, it would need to supply districts that serve 160,000 students weekly to meet the production goal, using the assumption of a 38-week school year. There are many possible combinations of school districts that could add up to this number, all of which generate different regional geographies of supply. One approach would be to simply supply the nearest urban area-Wake County (home to North Carolina's capital)—which has 158,000 students. On the other hand, if Working Landscapes were to prioritize serving the rural and smaller metropolitan counties that immediately surround it, it would need to serve 21 counties to achieve its goal. These hypothetical scenarios illustrate the point that, for an alternative food system intermediary like Working Landscapes, the scope of the "regional food system" is mutable: it is defined by the intersection of mission, market, and strategy.

The organizations participating in the Growing Opportunities meeting also engage in regional endeavors of widely varying geographic scope. Of 26 organizations whose representatives completed the survey, all but one work in multiple counties within the project's eight-county focal region, meaning that their programs extend beyond their home county. The spatial extent of these organizations' activities ranges from two counties to all eight counties in the region. On average, they work in four counties. These results corroborate the finding that organizations define and implement regional initiatives at an array of scales.

\section{Collaboration (or Lack Thereof) among Regional Food Ventures}

We examined the degree to which food system organizations in northeastern North Carolina are currently collaborating regionally by conducting a social network analysis (SNA) of Growing Opportunities survey responses. SNA maps relationships identified by respondents, where each "node" or dot represents an organization, and arrows, or "edges" between the nodes indicate a relationship. The networks are "directed," meaning that an arrow from Node A to Node B would demonstrate that Organization A identified Organization B as a collaborator, but not necessarily the other way around. Not all organizations with nodes responded to the survey; the relationships encapsulated in both SNA analyses show the network from the perspective of survey respondents.

Figure 2 depicts the network when the relationships are categorized hierarchically by relationship strength, with possible strengths organized in the following way: (1) being acquainted (the weakest strength of relationship); (2) having exchanged information and/or resources (an intermediate strength of relationship), and/or (3) having collaborated on one or more projects (the strongest relationship). A bigger node indicates that the organization was identified as a partner by more respondents. Nodes that are closer together indicate a stronger relationship between those organizations.

Figure 2 shows that much of the network is connected, with two small portions of the network isolated from the rest. There are a few central nodes that receive a lot of incoming edges, while the majority of nodes are held to the network through a single relationship, meaning it would not be very easy for peripheral nodes to communicate with nodes across the network.

The density of a social network captures the level of connectedness between nodes across a network. It is the proportion of ties that are connected out of all possible ties that could exist, where a higher density means a more connected network and a density of one is a completely connected network. In social networks, a density 
Figure 2. Social Network Analysis of Food System Organizations Working in an Eight-County Region of Northeastern North Carolina; Node Size Reflects Number of "In-Degree" Connections

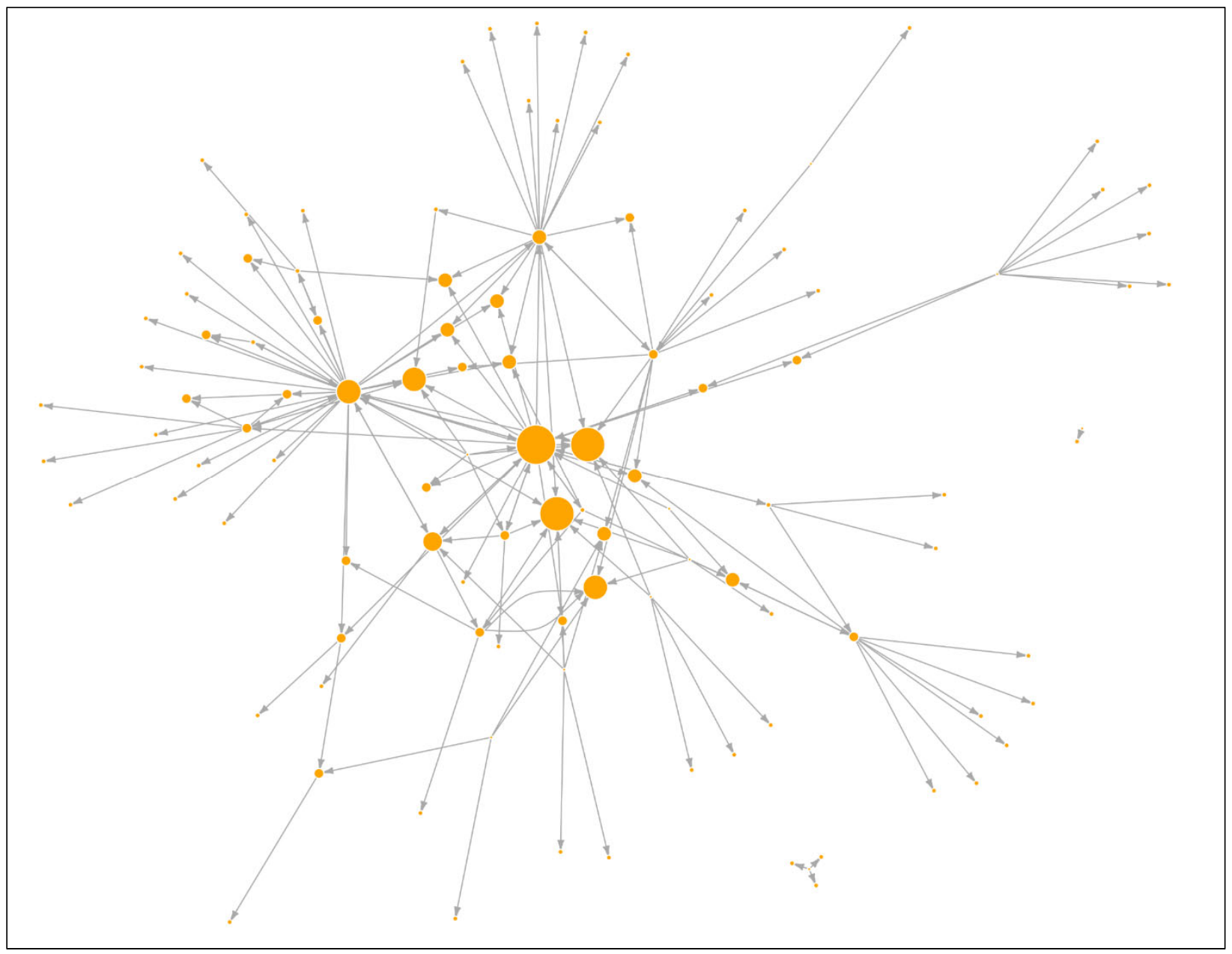

of .02 or higher is expected. The density of the network in Figure 2 is 0.014 - low for a social network-confirming the conclusion in our visual analysis that many of the nodes are not connected to one another. ${ }^{5}$

The network in Figure 3 illustrates one type of relationship: transactions of food. It is evident, first of all, that there are simply fewer nodes in this network, because only a subset of the food system organizations represented in the survey are directly involved in transacting food. Moreover, the relationships depicted compose not one interconnected network but rather eight small, disjunct networks. Among the nodes that are represented, there is one node that receives multiple incoming edges, while the majority are held to the network through a single edge.

Most of the nodes in this network are the same size, with the exception of one node that received a few more incoming edges. The very smallest nodes indicate that those nodes were not listed by any other organization as having a relationship, likely partially because not all organizations represented in this diagram responded to the survey. However, for the most part, the network is directed by a few players. With respect to density, the transactive network is slightly more dense than the preceding relationship network, with a score of 0.018 (likely due

${ }^{5}$ For a network with $\mathrm{N}$ nodes and M edges, Density $=\frac{M}{N(N-1)}($ Kolaczyk \& Csardi, 2014). 
Figure 3: Social Network Analysis (SNA) of Food Transaction Relationships among Food System Organizations Working in an Eight-County Region of Northeastern North Carolina Node size reflects incoming relationships.

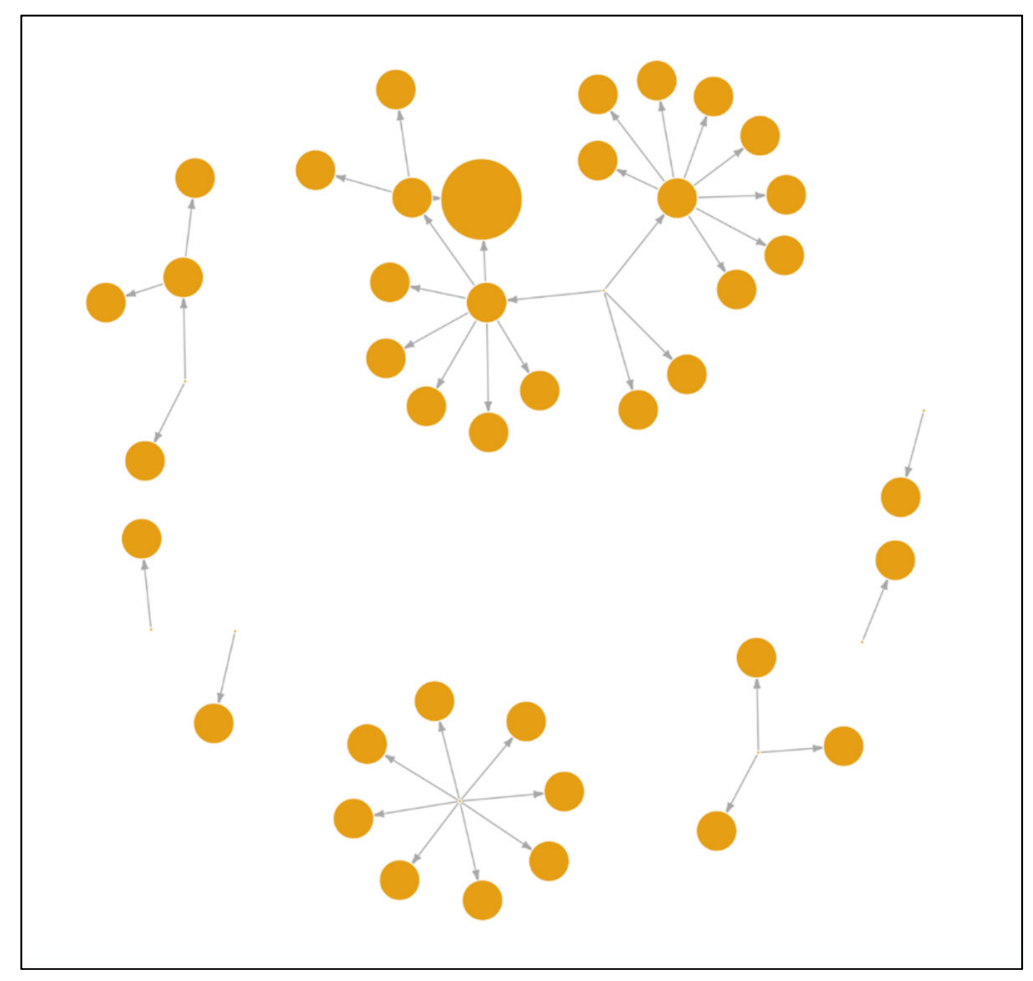

widely shared concern.

\section{Organizations Are Not Acbieving their Regional Food System Goals}

No interviewee reported fully achieving regional value chain development goals. Farmers lack access to markets, foodservice operators and retailers lack enough regional suppliers, and intermediaries lack connections with suppliers and customers. One interviewee, a university official, explained that, "The greatest obstacle I see of [my university] purchasing more local food for its students is the availability. I don't think it's cost. It's really just opportunity to purchase those items." No organizations reporting a numerical target for regional sourcing had achieved its target.

Additionally, stakeholders do not believe that the potential social, economic, and ecological benefits of the region's food system are being realized. As part of the written survey,

to the lower number of possible connections overall), but this is still below the minimum expected threshold for a social network (0.02).

In short, the social network analyses paint a picture of a region whose food system actors are partially but incompletely networked. A few central actors are connected to many others, but most actors are not well connected. This finding of the SNAs is corroborated by interview data: despite all being active in food systems initiatives in northeastern North Carolina, the interviewees have few value chain partners in common. This reinforces the view that the development of this region's value chains is being pursued in a highly fragmented way.

Meeting participants identified collaboration as a top priority. In a facilitated discussion, they were prompted to identify what would be needed to build a stronger regional food system. These ideas were then grouped to identify key issues. Through this process, "need for greater communication/ collaboration/trust-building" emerged as the most
Growing Opportunities meeting participants rated the degree to which northeastern North Carolina's current regional food system is achieving an array of goals adapted from Whole Measures for Community Food Systems (Community Food Security Coalition, 2009). This planning and evaluation tool is designed to aid communities in taking an integrated, whole-systems approach to food systems efforts by considering social equity, biodiversity, civic engagement, economic vitality, and other values. Responses are summarized in Table 1.

A slim majority of respondents see the region's food system as benefiting local communities. Respondents see less progress in other areas, especially food access.

In sum, food system organizations do not yet regard their regional endeavors as having produced the desired results in northeastern North Carolina, in terms of either the development of value chains or achievement of social benefits. 
Table 1. Growing Opportunities Meeting Participants' Levels of Agreement with Statements about the Benefits Derived from Northeastern North Carolina's Existing Food System

\begin{tabular}{lc}
\hline Northeastern North Carolina's current food system... & $\begin{array}{c}\text { Percent of } \\
\text { respondents in } \\
\text { agreement }\end{array}$ \\
\hline$\ldots$ contributes to the strength of the region's communities & $54 \%$ \\
\hline$\ldots$ supports the vibrancy of family farmers & $38 \%$ \\
\hline$\ldots$ supports thriving economies & $31 \%$ \\
\hline$\ldots$ is just and fair & $24 \%$ \\
\hline$\ldots$ sustains the health of our environment & $23 \%$ \\
\hline$\ldots$ provides healthy food to everyone & $13 \%$ \\
\hline
\end{tabular}

funding.

\section{Building Constituencies for Regional Food Initiatives}

A central challenge of building a regional food system is that, as our research illustrates, regional food systems are not just larger local food systems; they are qualitatively different. Local food initiatives tend to stem from their initiators' pre-existing, non-economic, placebased commitments. Regional food initiatives represent strategic linkages over greater geographic distances, to satisfy market needs or mission-driven mandates that cannot be adequately fulfilled within a local geography.

The differences between local and regional food systems are neither good nor bad; they are artifacts of scale. Neither is regional food system development a betrayal of the values that motivate local food system development; our research indicates that regional initiatives typically represent efforts to extend and sustain those values. However, the greater distances involved in regional food value chains, as well as the relative invisibility of regional food system actors from each other and external publics, present a marketing challenge for regional food systems. The archetype of the alternative food system is a farmer at a farmers market or roadside stand: the familiar face of a trusted community member who grew her wares herself nearby. This kind of hyperlocal, DTC value chain appeals to consumers. Regional food is a harder sell. Regional value chains are typically longer, representing participants who are likely not from a consumer's community and are thus unfamiliar.

Moreover, multistep regional value chains include participants (e.g., aggregators, processors, and distributors) whose existence may be unknown to consumers. Even when foods are sourceidentified and the identity of the supplier is presented directly to the consumer, only the farmer is typically represented. Value chains that render visible the people in the middle-delivery truck drivers, processing plant workers, food safety 
managers, etc.- - are exceedingly rare. This presents a challenge for regional food system development: regional value chains lack some of the charisma of "local food," while still being unable to match the low prices of globalized supply chains.

In addition to regional value chains being less visible to customers, regions themselves currently inspire little loyalty. For governmental and institutional representatives with geographically delimited jurisdictions, such as county and municipal officials, local food policy councils, or school nutrition directors, the preference for local food is not just aesthetic; it is political. Supporting food suppliers from within one's own jurisdiction is politically advantageous. Regions lack the rhetorical advantages of counties and states, whose boundaries are reinforced by political authority.

The fact that different regional food initiatives are viable at different scales further compounds the problem of fostering understanding of and support for regional food system development. There is not a uniform food "region" that advocates can readily direct attention toward; instead, the region served by each initiative and value chain is different. Rather than fitting the initiative to the geography, many regional food innovators are fitting the geography to the initiative.

Building constituencies for regional food value chains, then, requires educating consumers, public officials, and other stakeholders on the value of investing in food systems that are scaled to enable the emergence of viable food infrastructure and ventures - even if that scale does not correspond to their preexisting sense of place or political affiliations. Stakeholders will have to look past the short-term appeal of a particular sourcing story to the longer-term appeal of having invested in a resilient food system.

\section{Establishing an Enabling Environment for Regional Food System Development}

Given the lack of widespread public understanding of and support for regional food system initiatives, organizations such as those included in our study are essentially forging their own paths without the benefit of navigational aids. This uncoordinated approach reduces the impact of participating organizations while increasing risks of inefficiency, redundancy, and competition. While stakeholder engagement projects like Growing Opportunities have begun to improve coordination through peer-topeer networking, a need remains for planning and funding food systems at a regional scale_creating an enabling environment for regional food system organizations.

Efforts to foster regional food system planning and funding will confront the challenges discussed above: regional food value chains are poorly understood and variable in scale, while regional affiliations and institutions are weak. Overcoming these problems will require agreement upon defined food regions that can provide a shared, legible basis for coordinated planning and investment. Obviously, the scale of these regions is subject to debate. Our research strongly indicates that initiatives confined to individual counties or municipalities are likely to be too small to enable the development of sustainable intermediated food value chains, while statewide initiatives are too large to align with the value chains that many place-based organizations are now developing. Given the demonstrated ability of urban markets to propel value chain development, planning and funding regions scaled to encompass urban centers and adjoining rural regions hold considerable potential. Regional entities such as councils of government have jurisdictions that could support regional food system development at this scale - and some have begun to demonstrate leadership in this regard. These existing regional agencies could be given additional powers to plan food system infrastructure and prioritize projects for funding. Then, funders, both governmental and private, could use those regional plans to coordinate their investments, thus promoting the development of complementary, rather than redundant or competitive, initiatives.

A more planned, coordinated approach to regional food system development would admittedly reduce the heterogeneity, and therefore perhaps some of the creativity, that characterize today's nascent food regions. However, it would bring with it something that today's food system stakeholders sorely lack: certainty. If farmers and food system intermediaries were confident that their regional initiatives enjoyed public support and 
that the region's institutions were committed to purchasing the food they produced, then participation and collaboration in regional food system development would doubtless accelerate.

\section{Conclusion}

From the vantage point of northeastern North Carolina, regional food systems hold tremendous potential. They are different from local food systems, but they represent an extension of, not a departure from, the local food initiatives from which they have sprung. Like local food initiatives, regional food initiatives are designed to boost the vitality of rural communities, creating employment while connecting small farmers to new markets. They have the potential to increase consumers' access to healthy, fresh foods, with attendant health benefits. Though regional value chains are typically longer than local ones, it is still possible to achieve high levels of traceability that educate consumers about the origins of their food. It is further possible, though not guaranteed, that regional food systems can provide more just and ecologically sustainable alternatives to conventional food systems.

While remaining true to many of the commitments that have motivated local food systems initiatives, regional food systems can offer distinct benefits. They offer greater potential for economic viability, especially in rural regions. They also offer the potential to provide significant quantities of food to institutions and wholesalers, therefore increasing access to fresh, regionally sourced food where people regularly eat and shop.
Beyond economics, regional food system initiatives enable a distinct set of relationships. Regional food system development connects people not because they are from the same locale but because of complementary interests, expertise, and aspirations. In this way, regional food system work can facilitate the development of regional practitioner networks that will spearhead further development of these systems. This has the potential to be particularly valuable across rural regions.

Despite their value, regional food system initiatives remain poorly understood and inadequately supported; therefore, they are not yet living up to their potential. We see a need for more applied research on regional food system initiatives in order to improve understandings of their distinct properties, strengths, and limitations. This study has focused on a single, rural region; comparative research across regions, along with further research comparing urban and rural-based initiatives, would add valuable new dimensions. Further regional food systems research will be valuable in guiding much-needed regional food system planning efforts, which in turn will give food system initiatives a better chance of success.

\section{Acknowledgments}

The authors wish to thank all the participants in the Growing Opportunities project for their time, insights, and collaboration. We are also grateful to two anonymous reviewers whose feedback improved this paper.

\section{References}

Blay-Palmer, A., Santini, G., Dubbeling, M., Renting, H., Taguchi, M., \& Giordano, T. (2018). Validating the city region food system approach: Enacting inclusive, transformational city region food systems. Sustainability, 10(5), 1-23. https://doi.org/10.3390/su10051680

Born, B., \& Purcell, M. (2006). Avoiding the local trap. Journal of Planning Education and Research, 26, $195-207$. http://doi.org/10.1177/0739456X06291389

Clancy, K., Bonanno, A., Canning, P., Cleary, R., Conrad, Z., Fleisher, D., \& Tichenor, N. (2017). Using a market basket to explore regional food systems. Journal of Agriculture, Food Systems, and Community Development, 7(4), $163-178$. https://doi.org/10.5304/jafscd.2017.074.018

Clancy, K., \& Ruhf, K. Z. (2018). Digging deeper: New thinking on “regional.” Journal of Agriculture, Food Systems, and Community Development, 8(3), 13-17. https://doi.org/10.5304/jafscd.2018.083.008

Community Food Security Coalition (2009). Whole measures for community food systems. Portland, Oregon: Community Food Security Coalition. 
Cumming, G., \& Holland, D. (2013). Growing local/buying local: Challenging pessimism and social division through narratives of possibility. Progressive Planning, Spring(195), 43-46. https://www.plannersnetwork.org/2013/06/spring-2013-the-american-south/

Cumming, G., \& Norwood, C. (2012). The community voice method: Using participatory research and filmmaking to foster dialog about changing landscapes. Landscape and Urban Planning, 105(4), 434-444. http://doi.org/10.1016/j.landurbplan.2012.01.018

Desjardins, E. (2010). The urban food desert: Spatial inequality or opportunity for change? In A. Blay-Palmer (Ed.), Imagining sustainable food systems: Theory and practice (pp. 87-111). Burlington, Vermont: Ashgate Publishing Limited. https://doi.org/10.4324/9781315587905-6

Donald, B. (2008). Food systems planning and sustainable cities and regions: The role of the firm in sustainable food capitalism. Regional Studies, 42(9), 1251-1262. http://doi.org/10.1080/00343400802360469

Drabenstott, M. (2001). New policies for a new rural America. International Regional Science Review, 24(1), 3-15. http://doi.org/https://doi.org/10.1177/016001701761012962

Drewnowski, A., \& Specter, S. E. (2004). Poverty and obesity: The role of energy density and energy costs. The American Journal of Clinical Nutrition, 79(1), 6-16. https://doi.org/10.1093/ajcn/79.1.6

Dunning, R., Bloom, J. D., \& Creamer, N. (2015). The local food movement, public-private partnerships, and food system resiliency. Journal of Environmental Studies and Sciences, 5(4), 661-670. http://doi.org/10.1007/s13412-015-0295-z

Feenstra, G. (2002). Creating space for sustainable food systems: Lessons from the field. Agriculture and Human V alues, 19(2), 99-106. https:/ / doi-org.libproxy.lib.unc.edu/10.1023/A:1016095421310

Flegal, K., Carroll, M., Kit, B., \& Ogden, C. (2012). Prevalence of obesity and trends in the distribution of body mass index among US adults, 1999-2010. Journal of the American Medical Association, 307(5), 491-497.

https://doi.org/10.1001/jama.2012.39

Food Solutions New England. (n.d.). Retrieved from http://www.foodsolutionsne.org/

Fryar, C., Carroll, M., \& Ogden, C. (2012). Prevalence of overweight, obesity, and extreme obesity among adults: United States trends 1960-1962 through 2009-2010. Hyattsville, Maryland: U.S. National Center for Health Statistics. Retrieved from https://www.cdc.gov/nchs/data/hestat/obesity_adult_13_14/obesity_adult_13_14.pdf

Gwin, L., \& Thiboumery, A. (2014). Beyond the farmer and the butcher: Institutional entrepreneurship and local meat. Journal of Agriculture, Food Systems, and Community Development, 4(2), 81-96. http://dx.doi.org/10.5304/jafscd.2014.042.007

Hardesty, S., Feenstra, G., Visher, D., Lerman, T., Thilmany-McFadden, D., Bauman, A., .. . Rainbolt, G. N. (2014). Values-based supply chains: Supporting regional food and farms. Economic Development Quarterly, 28(1), 17-27. http://doi.org/10.1177/0891242413507103

Hinrichs, C. C. (2000). Embeddedness and local food systems: Notes on two types of direct agricultural market. Journal of Rural Studies, (16), 295-303. https://doi.org/10.1016/S0743-0167(99)00063-7

Hinrichs, C. (2003). The practice and politics of food system localization. Journal of Rural Studies, 19, 33-45. http://dx.doi.org/10.1016/S0743-0167(02)00040-2

Iloh, C. (2016). Exploring the for-profit experience: An ethnography of a for-profit college. American Educational Research Journal, 53(3), 427-455. https://doi.org/10.3102/0002831216637338

Inman, P. (2015). Regional food systems as engines for sustainable economies: How do universities engage? Social Alternatives, 34(2), 39-46.

Isserman, A. M. (2001). Competitive advantages of rural America in the next century. International Regional Science Review, 24(1), 38-58. Retrieved from http://journals.sagepub.com.libproxy.lib.unc.edu/doi/pdf/10.1177/016001701761013006

Isserman, A. M. (2005). In the national interest: Defining rural and urban correctly in research and public policy. International Regional Science Review, 28(4), 465-499. http://doi.org/10.1177/0160017605279000

Janssen, B. (2010). Local food, local engagement: Community-supported agriculture in Eastern Iowa. Culture \& Agriculture, 32(1), 4-16. http://doi.org/10.1111/j.1556-486X.2010.01031.x 
Kelly, M., Lang, H., Bhandal, G., \& Electris, C. (2012). Worker and social equity in food and agriculture: Practices at the 100 largest and most influential U.S. companies. Retrieved October 18, 2018, from

https://democracycollaborative.org/content/worker-and-social-equity-food-and-agriculture-practices-100-largestand-most-influential-us

Kirschenmann, F., Stevenson, G. W., Buttel, F., Lyson, T. A., \& Duffy, M. (2008). Why worry about the agriculture of the middle? In T. A. Lyson, G. W. Stevenson, \& R. Welsh (Eds.), Food and the mid-level farm: Renewing an agriculture of the middle (pp. 3-22). Cambridge, Massachusetts: MIT Press. https://doi.org/10.7551/mitpress/9780262122993.003.0001

Kish, Z., \& Fairbairn, M. (2018). Investing for profit, investing for impact: Moral performances in agricultural investment projects. Environment and Planning A: Economy and Space, 50(3), 569-588. http://doi.org/10.1177/0308518X17738253

Kneafsey, M., Ilbery, B., \& Jenkins, T. (2001). Exploring the dimensions of cultural economies in rural West Wales. Sociologia Ruralis, 41(3), 296-310. https://doi.org/10.1111/1467-9523.00184

Kolaczyk, E. D., \& Csardi, G. (2014). Statistical analysis of network data with R. Retrieved from https://doi.org/10.1007/978-1-4939-0983-4

Lengnick, L., Miller, M., \& Marten, G. G. (2015). Metropolitan foodsheds: A resilient response to the climate change challenge? Journal of Environmental Studies and Sciences, 5(4), 573-592. https://doi.org/10.1007/s13412-015-0349-2

Lev, L., \& Stevenson, G. W. (2011). Acting collectively to develop midscale food value chains. Journal of Agriculture, Food Systems, and Community Development, 1(14), 119-128. https://doi.org/10.5304/jafscd.2011.014.014

Lincoln, Y., \& Guba, E. (2000). Paradigmatic controversies, contradictions, and emerging confluences. In N. Denzin \& Y. Lincoln (Eds.), Handbook of Qualitative Research (2nd ed.) (pp. 163-188). New York: SAGE Publications.

Low, S. A., Adalja, A., Beaulieu, E., Key, N., Martinez, S., Melton, A., . . Jablonski, B. (2015). Trends in U.S. local and regional food systems (Report No. AP-068). Washington, D.C.: U.S. Department of Agriculture, Economic Research Service. Retrieved from https://naldc.nal.usda.gov/download/60312/PDF

Marshall, C., \& Rossman, G. B. (2016). Designing qualitative research. Los Angeles, California: SAGE.

Martin, P. (2003). Promise unfulfilled: Unions, immigration, and farm workers. Ithaca, New York: Cornell University Press.

Norwood, C., \& Cumming, G. (2012). Making maps that matter: Situating GIS within community conversations about changing landscapes. Cartographica, 47(1), 34-51. https://doi.org/10.3138/carto.47.1.2

Pansing, C., Wasserman, A., Fisk, J., Muldoon, M., Kiraly, S., \& Benjamin, T. (2013). North American food sector, part one: Program scan \& literature review. Arlington, VA: Urban Sustainability Directors Network. Retrieved from http://www.sfplanning.org/ftp/files/Citywide/Food System Policy Program/foodsys Program Scan Literature Review.pdf

Pirog, R., Miller, C., Way, L., Hazekamp, C., \& Kim, E. (2014). The local food movement: Setting the stage for good food. Lansing: Michigan State University Center for Regional Food Systems. Retrieved from http:/ / foodsystems.msu.edu/resources/local-food-movement-setting-the-stage

PolicyLink. (2001). Equitable development toolkit: Access to bealthy food. Retrieved from http://www.policylink.org/sites/default/files/access-to-healthy-food.pdf

Ranger, S., Kenter, J., Bryce, R., Cumming, G., Dapling, T., Lawes, E., \& Richardson, P. (2016). Forming shared values in conservation management: An interpretive-deliberative-democratic approach to including community voices. Ecosystem Services, 21, 310-323. https://doi.org/10.1016/j.ecoser.2016.09.016

Schlosser, E. (2001). Fast food nation: The dark side of the all-American meal. New York: Houghton Mifflin Company.

Stevenson, G. W., Clancy, K., King, R., Lev, L., Ostrom, M., \& Smith, S. (2011). Midscale food value chains: An introduction. Journal of Agriculture, Food Systems, and Community Development, 1(4), 27-34. http://dx.doi.org/10.5304/jafscd.2011.014.007

Stevenson, G. W., \& Pirog, R. (2008). Values-based supply chains: Strategies for agrifood enterprises of the middle. In T. A. Lyson, G. W. Stevenson, \& R. Welsh (Eds.), Food and the Mid-Level Farm: Renewing Agriculture of the Middle (pp. 121). http://doi.org/10.7551/mitpress/9780262122993.001.0001 
Tewari, M., Kelmenson, S., Guinn, A., Cumming, G., \& Colloredo-Mansfeld, R. (2018). Mission-driven intermediaries as anchors of the middle ground in the American food system: Evidence from Warrenton, NC. Culture, Agriculture, Food and Environment, 40(2), 114-123. http://doi.org/10.1111/cuag.12175

Truehaft, S., \& Karpyn, A. (2010). The grocery gap: Who has access to healthy food and why it matters. Policy Link and The Food Trust. Retrieved from http://www.policylink.org/atf/cf/\%7B97C6D565-BB43-406D-A6D5ECA3BBF35AF0\%7D/FINAL\%20GroceryGap.pdf\%20U.S.

U.S. Environmental Protection Agency. (2013). National greenhouse gas emissions data. Retrieved September 1, 2013 , from http://www.epa.gov/climatechange/ghgemissions/usinventoryreport.html

Walker, R., Keane, C., \& Burke, J. (2010). Disparities and access to healthy food in the United States: A review of food deserts literature. Health \& Place, 16, 876-884. https://doi.org/10.1016/i.healthplace.2010.04.013

Watson, J., Treadwell, D., \& Bucklin, R. (2018). Economic analysis of local food procurement in southwest Florida's farm to school programs. Journal of Agriculture, Food Systems, and Community Development, 8(3), 61-84. https://doi.org/10.5304/jafscd.2018.083.011

Whatmore, S. J., Stassart, P., \& Renting, H. (2003). What's alternative about alternative food networks? Environment and Planning A, 35, 389-391. http://doi.org/10.1068/a3621

Whitfield, S., Challinor, A. J., \& Rees, R. M. (2018). Corrigendum: Frontiers in climate smart food systems: Outlining the research space. Frontiers in Sustainable Food Systems, 2, 1-5. http://doi.org/10.3389/fsufs.2018.00075

Wolfe, D. W., DeGaetano, A. T., Peck, G. M., Carey, M., Ziska, L. H., Lea-Cox, J., . . Hollinger, D. Y. (2018). Unique challenges and opportunities for northeastern US crop production in a changing climate. Climatic Change, 146(1-2), 231-245. https://doi.org/10.1007/s10584-017-2109-7 